\title{
Research on the Application of Modern Educational Technology In Mathematical Education in High School
}

\author{
Liu Ying ${ }^{1}$, Li Na ${ }^{1}$, Zhao Jian Dong ${ }^{1}$ \\ ${ }^{1}$ Qingdao Huanghai University, Qingdao, Shandong, China
}

Keywords: Application, Modern Educational Technology, Mathematical Education, High School

\begin{abstract}
In this paper, the author elaborated the definition of modern educational technology and characteristics of high school mathematics education, analyzed the mode and shortcomings of the Traditional Mathematics Teaching Mode in High School. And the authors also analyzed the advantages of applying modern educational technologies into high school teaching practices. The study results showed that great importance should be attached to the application of modern information technology in high school educations, so as to effectively change the mode of teaching, to improve the teaching process, and get rid of teacher-centered teaching situation.
\end{abstract}

\section{Introduction}

In recent years, countries around the world have accelerated the process of education information, have the computer and other information technology in high School mathematics education, attaches great importance to research and practice of computer-assisted teaching. Future competition between countries is competition competitive economic strength, science and technology, which in the final analysis is the talent competition, depending on education and training of personnel. High-tech era of knowledge economy, is to keep high-tech comprehensive strength and competitiveness of a country or nation of the key factors, and is essentially a mathematical technique of high-tech, knowledge-based economy in order to mark the successful application of mathematics. Therefore, the strengthening of mathematics education, is an important part of the implementation strategy.

Primary education in an important position in the whole of education, the quality and level of development of primary education development, not only affect the entire education, but also to the future of socialist modernization. In the 21st century, our country will be more emphasis on primary education. This raises the strengthening of high School teaching reform and explore new ideas task. To cultivate talents for the 21st century global inquiry found that the core task is to develop a high order of talent. For train talented, high School mathematics education plays an irreplaceable role. Therefore, in teaching how to develop modern means of education students' potential, training creative aspects of high School mathematics education reform is worthy of serious consideration. High School Mathematics Teaching has its own distinct personality and teaching other subjects, because mathematics has its own unique characteristics of discipline: the discipline of human understanding of nature mediation, human development is an indispensable element is the human culture an important part; this discipline is one of the earliest human natural science developed, it has long played a leading role in the discipline. Currently, in addition to mathematics itself is still in continuous improvement and continue to develop, but also to other areas of infiltration, the formation of a large number of interdisciplinary combination with other disciplines, so that the world today many new discoveries, new inventions, new creation directly or indirectly related to mathematics. Thus, not only mathematics in science and technology play a huge role, but also in a large pool of science, environmental science, social science, humanities and even has an irreplaceable role.

\section{The Definition of Modern Educational Technology}

1994 American Association for Educational Communications and Technology educational technology to make the most simple and most comprehensive way: educational technology to 
promote learning of the relevant processes and resources to design, develop, theory and practice of use, management and evaluation. From a broader perspective, is generally believed that education and modern educational technology is the same concept can be generic, it does not have to be distinguished. From the narrow point of view, some scholars pointed out: modern educational technology especially in modern learning theory and ideological education as the basis, as a means of modern information technology, computer technology as the core media education. Modern educational technology referred to herein refers to the above-described second meaning.

\section{The Traditional Mathematics Teaching Mode in High School}

Over the years taken by high School mathematics teacher-centered teaching model, which is characterized by the teacher by telling, media assisted teaching and writing on the blackboard, the students or the teaching contents to teach students. The teacher is the master of the entire teaching process, students in a passive acceptance of the status of teachers instill knowledge. In such a model, the teacher is active teaching, students are passive recipients of external stimuli that is instilled object is to assist the media to equip students with the tools teacher, teaching is indoctrination content. Whether liberal arts, science, physics and chemistry is still the language, history, geography, as long as the teacher-centered teaching model, in which the four elements (teachers, students, teaching materials, media) will surely have such a stable structure. Teaching is based on five sections Kairov typical teacher-centered teaching mode, it has the advantage in favor of teachers play a leading role, help teachers to classroom organization, management and control; but it also has a large the flaw is that exaggerated the role of teachers, ignoring students 'initiative and creativity, not the students' cognitive main body of the application and practice of the role of modern educational technology in teaching high school mathematics is well reflected.

Teaching Content. Our high School mathematics textbooks from the material point of view, somewhat outdated; textbooks organization from the perspective of conventional treatment methods stick to mathematics, without considering the ability to accept secondary school applications and high school students. Such as geometry, Euclidean system emphasizes the traditional rigor and intuitive geometry integrated approach (and easy acceptance), that it is almost the only way to cultivate logical thinking ability of high School students. These views are not without reason, but in today's situation, whether single or from the entire high school mathematics textbook perspective, are really big debatable from geometry.

Teaching Model. At present, many secondary schools are using the class system, there are full-time theory, the experimental class teachers. Class teachers teach mainly explain, and explain ways to succinctly tell a little combination: a lesson often contain considerable knowledge points. There are also many secondary schools, under the guidance of modern education thought, teachers try to introduce some teaching model; such as: seminars, discuss style of teaching. However, the constraints of the traditional teaching ideas, such teaching mode in high School mathematics teaching is not broad face, and even some to lectures and seminars, there is no systematic teaching mode reform.

Learning Mode. In traditional teaching, most of the time occupied by the teacher in the classroom, the students had a lot of knowledge used to be a teacher output and poured a steady stream of his mind, usually too late to make too much thinking, a lot of content for the classroom in general after school to digest through a lot of exercises. But with the reform of the teaching model, students learn all these years has been improved, the students themselves think time increased noticeably. Thus there is an urgent need for a teaching model to guide students to think, through this model, to provide students with the best environment in which students can explore more proceed smoothly, avoiding unnecessary due to some objective factors that influence the students' enthusiasm to promote student active learning lively. Obviously, this new mode of teaching is inseparable from the use of modern educational technology.

\section{The Main Shortcomings of the Traditional Mathematics Teaching Mode in High School}


It Is Not Conducive to Creative Culture. In the traditional high school mathematics teaching mode, too played a dynamic role of teachers, year after year, day after day, the "concepts, definitions, theorems, formulas," and even the most cutting-edge scientific dynamic by a mouth, a only chalk, occasionally attached a few pictures, continue to lose students. For teachers, really hard, honed paying lip service to the whole class for abstract concepts, analyzed sentence by sentence, for Theorem incomprehensible, with plenty of examples repeated explanation. With painstaking to describe is not an exaggeration, however, to achieve the effect of teaching, our teachers' pay, and our expectations are always far away, we just want to teach the student contents of the books, but did not enable them to acquire "will learning "capability. Such an expansion of knowledge in the present, full of competitive society, over time, will be worrying viability. Another failure which is the traditional Education. Furthermore, the traditional mathematics teaching our students is formed over rational thinking, but too much reason to make students lose math "feel" indifferent Perception. With any mathematical problem, we are used to cool some of its first analysis, the lack of intuition, inspiration, and certainly no curiosity, suppressed creative play.

Personnel Constraints Diverse Culture. This results in the traditional mode of teaching is obvious. Since our single teaching mode, the direction of human development would have been about this teaching mode. Exaggeration to say that: Our students are pressing grown, starting from the time of Confucius, the students were told at the position to be told what to study, what to do and was told "family line" "excellent learning Shi" . It is now the most is to find a good job, so, in the established guidelines, the development of students toward the same goal. Traditional teaching, especially domestic mathematics teaching, it is difficult to mention highly educated, even at this level, it is only for a handful of "Health professionals" is concerned. We trained a few mathematical elite, but they ignore the social groups to improve the quality of mathematics. This is one of the drawbacks of traditional education.

It Does Not Help to Improve the Teaching Level. Mathematics Teaching itself is a creative activity, teachers over many years, using the same way, the lack of creativity, students are pressing learning, lack of innovation spirit, there would be too many problems for teachers. Student to teacher stress is the greatest force teachers to improve their own level and quality of teachers is no pressure, it is difficult to achieve self-improvement, in the long run, the aging structure of teachers' knowledge, behind the times, we can imagine, how can you expect students Welcome it? bound to be eliminated by the classroom era. The times are ahead, we should advance with the times. Should inherit the fine traditions, but also exposed the deficiencies should be corrected promptly. Like traditional education and traditional culture, directly or indirectly participate in the people's real life, and ubiquitous influence and restrict specific behavior of real people, positive or negative. Because of this, our inheritance is never completely copy, nor is negated, but the selection, on the basis of critical inheritance. We choose, critical inheritance results of previous studies based on the aim of innovation.

\section{The High School Mathematics Teaching in the Modern Educational Technologies}

According to the US AECI, defined in 1994, is a technology education / learning process and learning resources theory and practice of design, development, use, management and evaluation. The study is to learn the process of educational technology and learning resources, research theory and practice. Theoretical system of educational technology involves philosophy, teaching theory, learning theory, communication theory, electronic theory, aesthetic theory and systems theory, information theory, cybernetics and so on. Practice of educational technology is to use scientific thinking, principles and methods to solve the education, the problems in the teaching process. It can be said is a comprehensive educational technology ideas, theories, techniques and methods. It is not a major concern of modern information technology itself, but rather a variety of modern technologies in education, teaching. It is not the pursuit of education of the machines, but the education of optimization. "Modern educational technology is the core of computer information technology in education and teaching applications in the field." Modern educational technology is a new feature of educational technology in the development of information society, marked by 
multimedia technology and network technology is widely used in education and teaching. Modern educational technology is to provide an environment conducive to observation, thinking, comparative information technology teaching environment, teaching software development helps to create resources for learners, teachers cultivate modern sense of innovation, to carry out the teaching experiment, explore and build create a new model of education, to train students to be "positive difference, keen observation, rich imagination, the quality of the knowledge structure of the personality" of the people. Needless to say, modern educational technology is the commanding heights of educational reform and development and a breakthrough toward modernization of education is an indispensable way.

\section{Conclusions}

Computers and other information technology into the classroom to provide students with a rich and vivid learning resources, but also for the students involved in providing favorable conditions to become a powerful tool for learners to discover knowledge, to explore the knowledge and express their views, and for teachers to teach students learn both provide a good technical support, we should give full play to the advantages of information technology, effectively change the mode of teaching, improve the teaching process, in order to get rid of teacher-centered teaching situation for the student's personality and diversified learning contexts provided ,

\section{References}

[1] Huifang Zhou: Mathematics Education, Vol. 6 (2004) No 53, p.25-26

[2] Hongli Zhang: Mathematical Bulletin, Vol. 12 (2005) No 27, p.74-76

[3] Qin Guo: China Educational Technology, Vol. 1 (2006) No 33, p.11-14

[4] Jieming Liu: Guangxi Normal University, Vol. 3 (2007) No33, p.121-124

[5] Minghua Qin: Chinese Education Society, Vol. 8 (2010) No12, p.58-60 